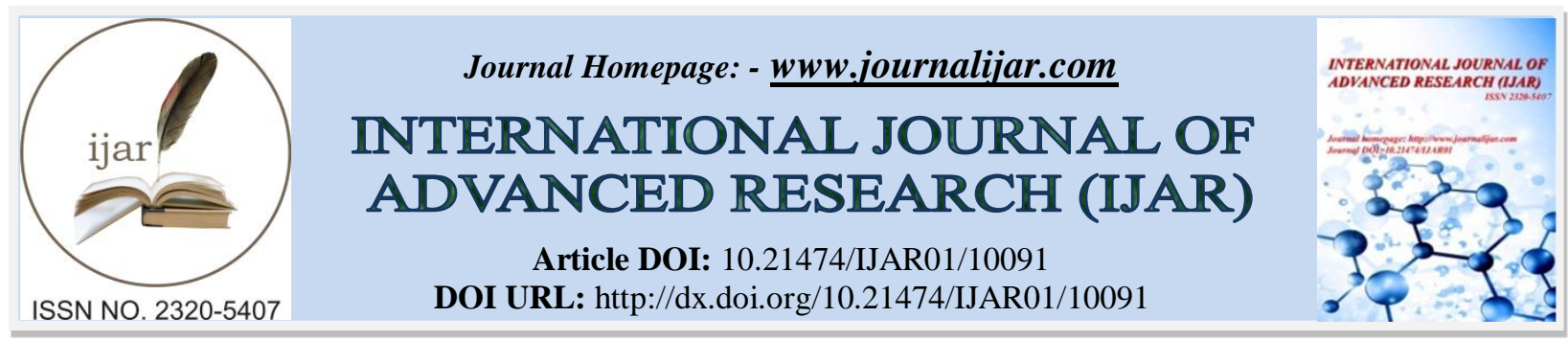

RESEARCH ARTICLE

\title{
ASSESSMENT OF NOISE EXPOSURE LEVEL OF SAWMILL WORKERS AT OGBOSISI AND MBIERI TIMBER AND ALLIED INDUSTRIAL MARKET IN OWERRI, IMO STATE.
}

\author{
Ebe T. E. ${ }^{1}$, Njoku-Tony R. F. ${ }^{1}$, Emereibeole E. I. ${ }^{1}$, Ihejirika C. E. ${ }^{1}$, Udensi j.U ${ }^{2}$., Ugwuegbu C. M. ${ }^{1}$ and
} Ezikudu C. E. ${ }^{1}$.

1. Department of Environmental Management, School of Environmental Sciences, Federal University of Technology, Owerri, Imo State.

2. Department of Biotechnology, School of Biological Sciences, Federal University of Technology, Owerri, Imo State.

\section{Manuscript Info}

Manuscript History

Received: 14 September 2019

Final Accepted: 16 October 2019

Published: November 2019

Key words:-

Noise, chronic, decibel, Pollution, effect.

\section{Abstract}

Noise as an unwanted sound, it reduces the quality of life and causes serious chronic or acute health problems. Therefore, there is need to access the noise level to which sawmill workers at the timber and allied industrial market are exposed to by comparing measured noise levels with regulatory standards. A digital sound level meter Lutron (Model SL-4030) and a global positioning system (GPS) -NAVA 300 was used to measure the sound level at the two study locations and the results were recorded in Decibel $(\mathrm{dB})$ for morning and afternoon working periods for six (6) days respectively. From the results, it was observed that all the locations sampled from station $\mathrm{A}$ to $\mathrm{E}$ were above the standard limits ( 96.15 to $101.65 \mathrm{~dB}$ ) for both morning and afternoon in Ogbosisi and similar levels were also observed at industrial Market Umuonyeali Mbieri (93.19 to 94.96). Thus all workers within these areas were exposed to noise hazards which affect their health and hearing ability. Therefore, workers and operators who visit the site regularly and spend long hours close to the noise sources were advised to use protective devices such as ear plugs, ear muffs, goggles and nose masks.

Copy Right, IJAR, 2019,. All rights reserved.

\section{Introduction:-}

The Timber Market is a place where timber is processed and sold, there is also a provision for welding work and sales of timber allied products, offloading of woods, restaurant, etc.

The woods are supplied from various states across the country including Edo, Cross River, Delta, Ondo, Akwa Ibom states of Nigeria by land transportation, thus the use of trailers, lorries etc being a necessity.

The woods are processed and prepared for sale using different machines like the table saw, planning machines, mortising and grooving machine, filing machines and the most important and main machine which is the spindle(sterner) machine.

Corresponding Author:-Ebe T. E.

Address:-Department of Environmental Management, School of Environmental Sciences, Federal University of Technology, Owerri, Imo State. 
The use of these and other machines, accompanied by the loading of timber and offloading of timber, use of dieselpowered engines, generates and constitute noise. Modern sound related health threats extend far beyond music (David, 2019), loudspeakers and automobiles (Narendra and Davar, 2017; Pandya, 2010) and they affect more than hearing.

High noise level can lead to cardiovascular effect in humans and an increase in incidence of coronary artery disease though night-time noise have more impact than day-time noise (Munzel et al., 2018). Examples of conditions that cause a conductive hearing loss include: ear wax (cerumen) that becomes impacted in the outer ear canal; a foreign object (e.g. bead) trapped in the ear canal, an infection (such as "swimmer's ear")in the ear canal, a rupture (hole) in the eardrum; fluid in the middle ear due to an ear infection, and or discontinuity in the chain of ossicles, ( Kathryn, 2002).

Materials And Method:-

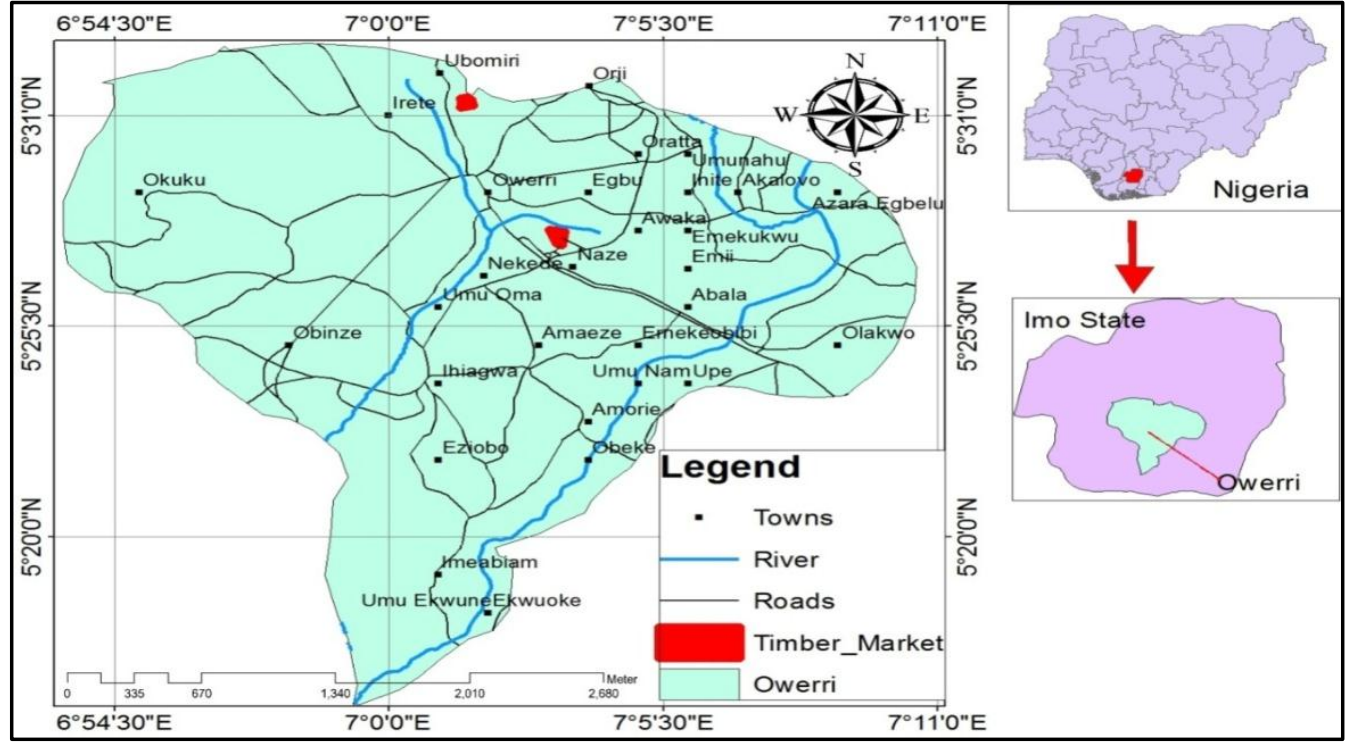

Fig. 2.1:-Map of the study area

The SL-4030 is a single hand held digital sound level meter used for measuring noise level in any environment. Data collected from the two sampling sites were compared with relevant standards. Overall morning and afternoon for six days values were computed and measured. Average of the six days for the two locations were calculated as mean values for the sampling sites. The morning and afternoon mean results were subjected to spatial interpolation to identify areas of high noise level. The analysis was done using the Inverse Distance Weighted (IDW) tool of Arc Tool-Box in the ArcMap.

\section{Results and Discussion:-}

\section{Results:}

Table 3.1:-Sampling points at Timber and Allied Market Naze.

\begin{tabular}{|l|l|l|l|l|}
\hline Longitude & Latitude & STATION: & MORNING & AFTERNOON \\
\hline 7.056758 & 5.460852 & A & 97.6 & 101.645 \\
\hline 7.056986 & 5.462786 & B & 98.155 & 98.43 \\
\hline 7.057174 & 5.464626 & C & 97.30667 & 96.15167 \\
\hline 7.055791 & 5.466184 & D & 95.55833 & 97.60667 \\
\hline 7.055321 & 5.463874 & E & 100.3967 & 100.08 \\
\hline
\end{tabular}




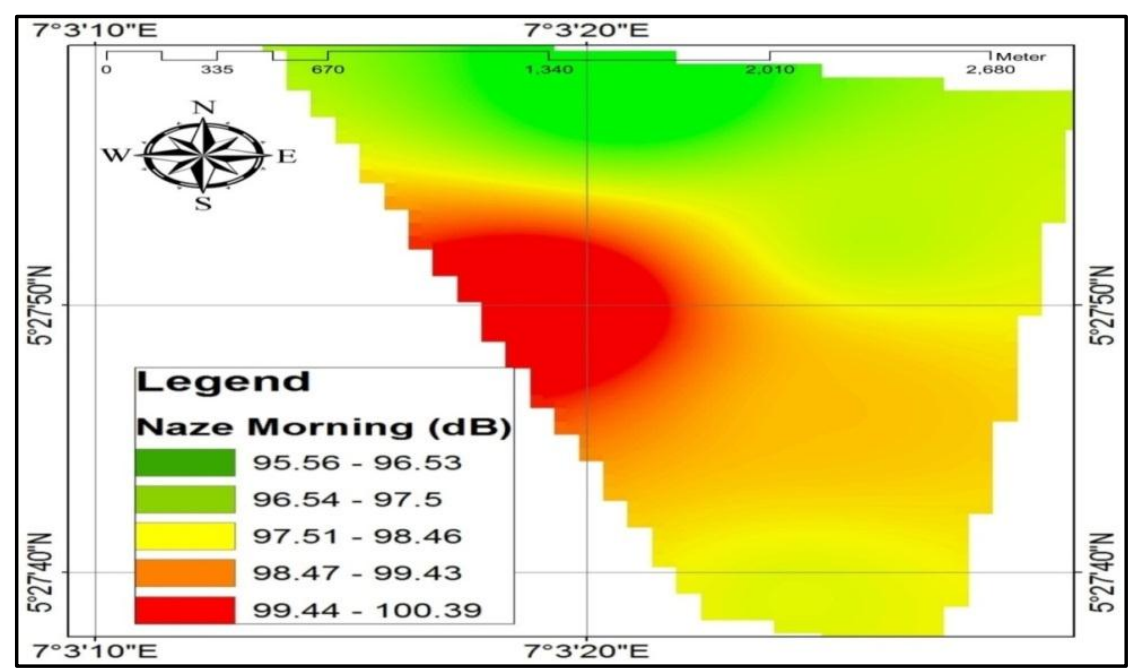

Fig 3.1:-Map of Industrial Regional Market Ogbosis, Naze, Morning Noise Level.

The noise measurement for the beginning of work period in the early hours of the morning was revealed in the figure 4.1 above. The noise level was segmented into five areas at $\mathrm{dB}(\mathrm{A})$ covering the five sampling points starting from $95.56 \mathrm{~dB}$ (A) to $100.39 \mathrm{~dB}$ (A). See the figure 4.1 above. From the IDW spatial interpolation results, it as revealed that the noise levels in the morning from the entire area were above limit and however, the western part of the market had the highest recorded noise.

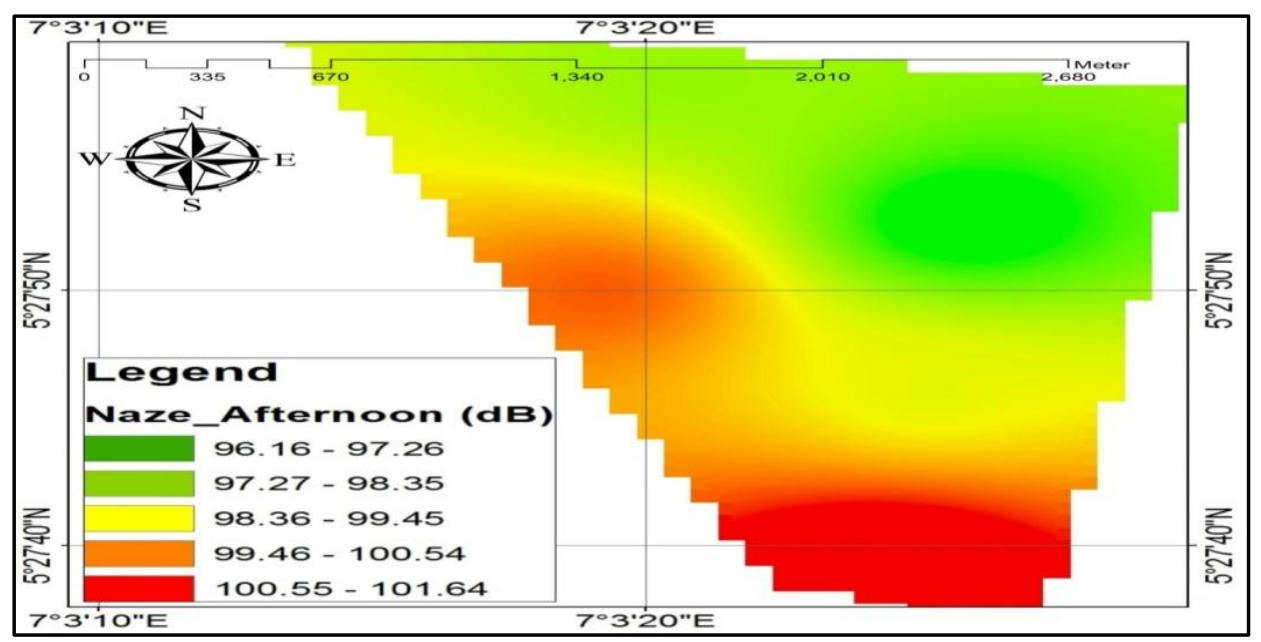

Fig 3.2:-Map of Industrial Regional Market Ogbosis, Naze, Afternoon Noise Level.

For the afternoon measurement, the noise measurement for the peak of work period in the afternoon was revealed an increased noise level within West and South region of the market (see the figure 4.2 above). The noise level was segmented as same with figure 4.1, which was into five (5) categories at $\mathrm{dB}(\mathrm{A})$ covering the five sampling points in the market starting from $96.16 \mathrm{~dB}(\mathrm{~A})$ to $101.64 \mathrm{~dB}(\mathrm{~A})$. See the figure 4.2. This figure was also an IDW spatial interpolation result of the afternoon noise measurements from the different sampling points in the market. It was revealed that in the afternoon, most machines used at that period were the highest sources of noise 


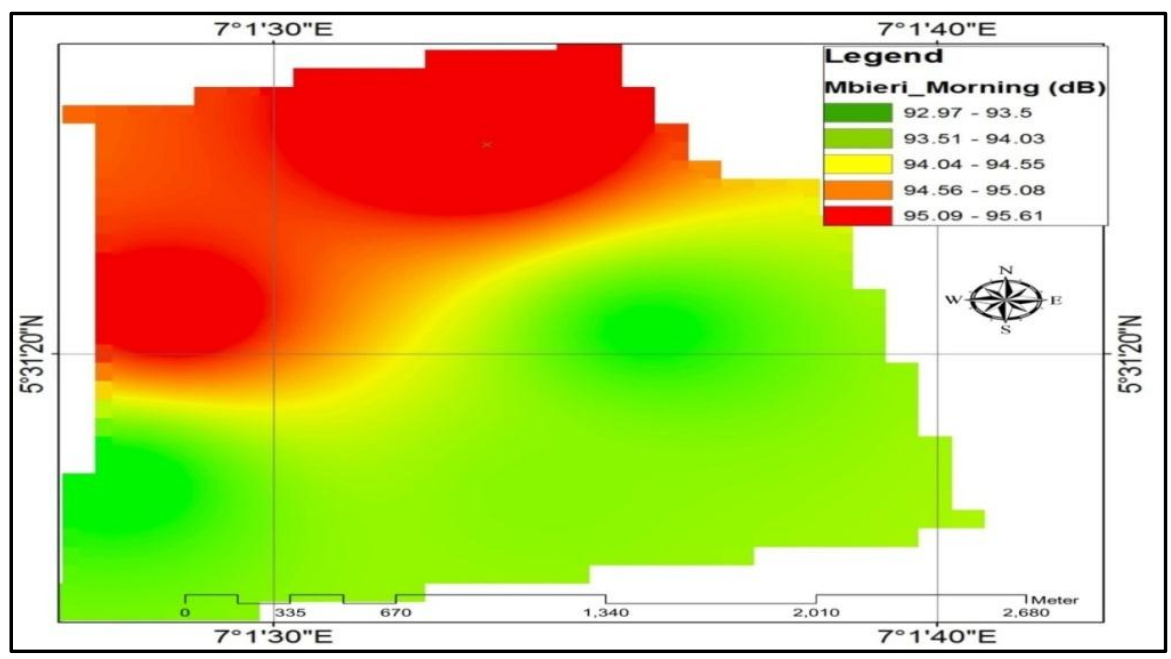

Figure 3.3:-Map of Industrial Market Umuonyeali Mbieri, Morning Noise Level.

The noise level measurement for morning hours of work in the Industrial Market Umuonyeali Mbieri was revealed in the figure 4.3. The noise level was segmented into five areas at $\mathrm{dB}(\mathrm{A})$ covering the five sampling points starting from $92.57 \mathrm{~dB}$ (A) to $95.61 \mathrm{~dB}$ (A). See the figure 4.3 above. From the IDW spatial interpolation results, it was revealed that the noise levels in the morning from the entire area were above FEPA limit and however, the western part of the market has the highest recorded noise.

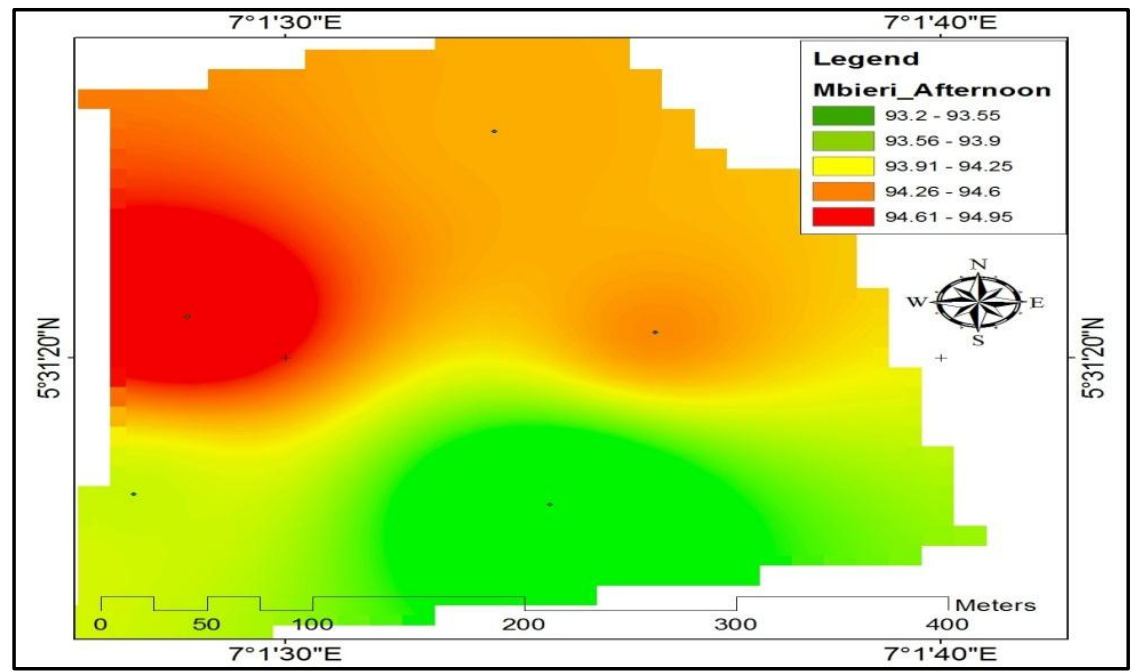

Figure 3.4:-Map of Industrial Market Umuonyeali Mbieri, Afternoon Noise Level.

For the afternoon measurement, the noise measurement for the peak of work period in the afternoon was revealed an increased noise level within West and north region of the market (see the figure 4.4 above). The noise level was segmented as same with figure 4.3 , which was into five (5) categories at $\mathrm{dB}(\mathrm{A})$ covering the five sampling points in the market starting from $93.2 \mathrm{~dB}(\mathrm{~A})$ to $94.95 \mathrm{~dB}(\mathrm{~A})$. See the figure 4.4. This figure was also an IDW spatial interpolation result of the afternoon noise measurements from the different sampling points in the market. It was revealed that in the afternoon, most machines used at that period were the highest sources of noise

\section{Discussion:-}

The 8 and 10 hours exposure limits for FEPA and OSHA standards were used to compare the results obtained from actual measurement of noise levels at selected stations in the study area(sawmill) because the workers spend upwards of 8 hours each day at the site. 
The average noise level measured in the cardinal directions during the study period exceeded FEPA or OSHA standards.

The measurement for 6 days varied because all the operators and traders do not begin work at the same time.

Many of the operators of noise-generating machines especially those who work with the spindle (stenner) machines from observation, already have symptoms of noise-induced hearing loss as most of them could not hear at sound level of normal conversation and so one has to increase her tone before they could hear or communicate with her very well and that confirms the report of Rilind (2019) that noise damage the brain, hearing power, poor sleep, psychological disorder, increased risk of cardiovascular diseases etc. Furthermore, noise pollution can lead to autistic spectrum disorder(ASD) which may cause hyperacusis (abnormal sensitivity to sound) (Stiegler and Davis, 2010). Menkiti and Agunwamba (2015) reported that average noise level of $97.60 \mathrm{~dB}$ exceeded the WHO standard of $50 \mathrm{~dB}$ allowed for residential areas. The location of these sawmill attracted people to build both their residential houses and private schools around the area thereby increasing the population that are exposed to this noise pollution The afternoon measurements indicated that the highest noise level is generated in the afternoon hours between 12 and $4 \mathrm{pm}$ when all machines and engines are in use, more buyers are in the market and more private and commercial vehicles move in and out of the area, especially those carrying wood and allied products. Road transportation plays a major role in the economic and social development of the country. With the increase in vehicle population, noise level will increase (Pandya, 2010). In the west direction, particularly at station D, a group of workers was observed filling wood with filling machines producing loud sounds. At station C, moving eastward, there is a road and lots of trucks and cars and trailers offloading woods moves around there and as such adding to the noise level in the area. At station A the diesel-powered engine that powers the machine is located there, which also causes the noise level in that area to increase.

Some of the noise-producing machines at the station include; generators, spindle molder machine, stenner machine, planning machines, mortising and grooving machines, sawing machines etc. Most workers were not considering the noise level as a problem as observed by Koushki et al., (2007). Though, some of them that were aware of the impact of noise on their health are there because of poverty and unemployment.

\section{References:-}

1. David Owen (2019). Is noise pollution the next big public health crisis? www.newyorker.comKathryn .H. Arehart (2002)," The nature of hearing and hearing loss" Durham, NC: Duke University press, 31-85.

2. Koushki, P. A., Kartam N. and Almutairi A. (2007) worker's perceptions \& awareness of noise pollution at construction sites in Kuwait. Civil Engineering \&Eval Systems 21.

3. Menkiti Nwasinachi, Agumwamba Jonah (2015). Assessment of noise pollution from electric generators in a high density residential area. African Journal of Science, Technology, Innovations and Development. 306-312.

4. Munzel T., Gori T., Babisch W. and Basner M. (2014). Cardiovascular effect of Environmental noise exposure. European Heart Journal. 6-7.

5. Stiegler, L. N. and Davis R. (2010). Understanding sound sensitivity in individuals with Autism spectrum disorder. Focus on Austism and other developmental disabilities. 25 (2): 67-75.

6. Narendra singh \& Davar S.C.(2017)Noise pollution-Sources, effects and control. Journal of human ecology Vol 16.

7. Pandya, G. H. (2010)Assessment of traffic noise and its impact on the community. International Journal of Environmental studies Vol 60

8. Rilind Elezaj (2019) Noise pollution effects.www.healtheuropa.eu. 